\title{
Total and domain-specific sitting time among employees in desk-based work settings in Australia
}

\author{
Jason A. Bennie, ${ }^{1,2}$ Zeljko Pedisic, ${ }^{2,3}$ Anna Timperio, ${ }^{4}$ David Crawford, ${ }^{4}$ David Dunstan, ${ }^{5,4}$ Adrian Bauman, ${ }^{2}$ \\ Jannique van Uffelen, ${ }^{1}$ Jo Salmon ${ }^{4}$
}

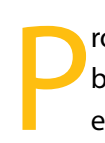
rolonged time spent in sedentary behaviours (e.g. too much sitting) has emerged as a new behavioural risk factor for chronic diseases, independent of the amount of time spent in leisure-time physical activity.' Sedentary behaviours are defined as "any waking behaviour characterised by an energy expenditure $\leq 1.5$ Metabolic Equivalents while in a sitting or reclining posture".2 Sedentary behaviour is often operationalised as self-reported sitting time in epidemiological studies. ${ }^{3}$ Reviews of epidemiological evidence suggest that individuals with regular high volumes of sitting time or other sedentary behaviours, such as watching TV, may be at an increased risk of all-cause and disease-specific mortality and chronic disease incidence (e.g. diabetes, cardiovascular disease). ${ }^{4-6}$ Importantly, some studies have shown that the associations between sitting time and mortality/ morbidity may occur regardless of whether an adult meets the public health physical activity recommendations of 150 minutes/ week of moderate-to-vigorous physical activity (MVPA). ${ }^{7-10}$ However, some recent studies failed to show such relationships. ${ }^{11,12}$ Nevertheless, some health authorities within Australia, the UK and the US have provided recommendations for decreasing daily sitting time among adults. ${ }^{13-15}$

Large-scale population prevalence studies have shown that, on average, adults report sitting for up to 5-6 hours a day, ${ }^{16,17}$ with younger adults and those with higher educational levels being among the most

\begin{abstract}
Objective: To describe the total and domain-specific daily sitting time among a sample of Australian office-based employees.

Methods: In April 2010, paper-based surveys were provided to desk-based employees ( $n=801)$ in Victoria, Australia. Total daily and domain-specific (work, leisure-time and transport-related) sitting time (minutes/day) were assessed by validated questionnaires. Differences in sitting time were examined across socio-demographic (age, sex, occupational status) and lifestyle characteristics (physical activity levels, body mass index [BMI]) using multiple linear regression analyses.
\end{abstract}

Results: The median (95\% confidence interval [Cl]) of total daily sitting time was 540 (531557) minutes/day. Insufficiently active adults (median $=578$ minutes/day, [95\%Cl: 564-602]), younger adults aged $18-29$ years (median $=561$ minutes/day, [95\%Cl: 540-577]) reported the highest total daily sitting times. Occupational sitting time accounted for almost $60 \%$ of total daily sitting time. In multivariate analyses, total daily sitting time was negatively associated with age (unstandardised regression coefficient $[B]=-1.58, p<0.001$ ) and overall physical activity (minutes/week) $(\mathrm{B}=-0.03, p<0.001)$ and positively associated with $\mathrm{BMI}(\mathrm{B}=1.53, p=0.038)$.

Conclusions: Desk-based employees reported that more than half of their total daily sitting time was accrued in the work setting.

Implications: Given the high contribution of occupational sitting to total daily sitting time among desk-based employees, interventions should focus on the work setting.

Key words: sitting, physical activity, epidemiology, employees, workplaces

at risk of accumulating higher volumes of sitting. ${ }^{16-18}$ Sitting occurs across numerous contexts on a daily basis, including occupational, educational, transport, domestic and leisure-time domains..$^{19} \mathrm{At}$ present, few studies have examined how an adult's sitting time is distributed across these domains. In order to fully understand sedentary behaviour and provide grounds for public health interventions, it is important to obtain prevalence estimates of not only the total amount of sitting, but also the context in which these behaviours occur. ${ }^{4}$ Identifying in which domain the majority of sitting occurs will inform potential settings or periods of the day when reductions in sitting can be targeted by intervention. For instance, if the majority of sitting occurs during transportation or while at work, then reducing sitting in these settings is likely to be a key intervention focus.

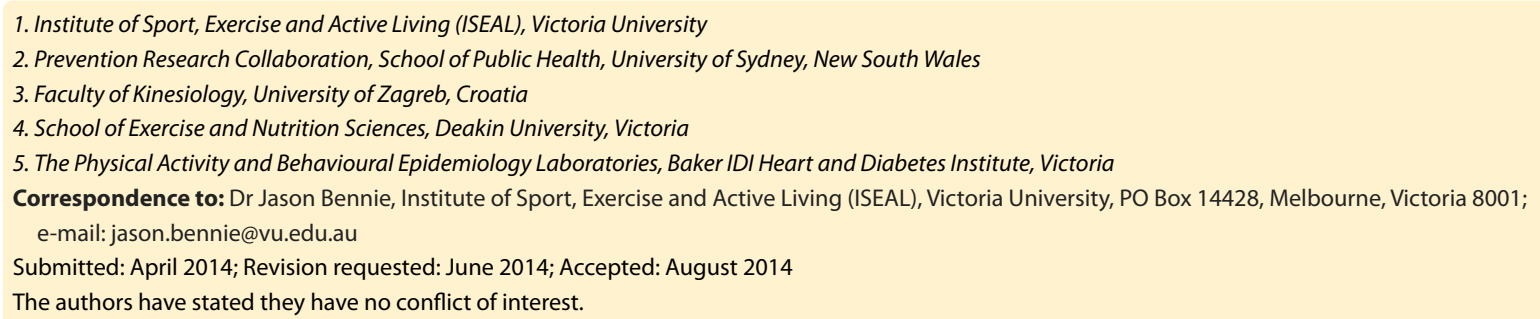


The work setting is important, given that employed adults spend more than half of their waking hours in the workplace. ${ }^{20}$ Available data from large-scale studies suggest that self-reported workplace sitting ranges between 180 to 300 minutes (3-5 hours) per day. ${ }^{21-23}$ However, objectively measured sitting time in smaller-scale studies using accelerometers and inclinometers estimates average sedentary behaviour or sitting time among desk-based employees of more than 360 minutes ( 6 hours) per day at work. ${ }^{24,25}$ Previous studies have suggested that the groups at the highest risk of prolonged workplace sitting include males, ${ }^{21}$ white collar employees ${ }^{21,22}$ and overweight/ obese individuals. ${ }^{23}$

Despite desk-based employees being a population group of interest, few Australian studies have investigated the pattern and correlates of their sitting time concurrently across all domains. Some studies of employees in desk-based settings have focused on time spent sitting in the occupational domain, ${ }^{23,24,26}$ the leisure-time domain ${ }^{26,27}$ and on overall total sedentary time. ${ }^{24,26,28}$ Assessments of transport-related sitting time this population are still lacking.

This study aimed to examine prevalence estimates of total and domain-specific sitting time among Australian desk-based employees, and to help inform who is most at risk of extended sitting time, and in which domain this occurs, by exploring its sociodemographic, health and physical activity correlates.

\section{Methods}

\section{Participants and recruitment}

Participants were recruited from a sample of workplaces in Melbourne, Australia, generated using a publicly available on-line business database (www.dnb.com.au), which contains more than 50,000 private and public companies in Australia. Workplaces were included in the final sampling framework if they had at least 500 employees in total (including desk-based and non-desk-based employees). The final sampling framework consisted of 316 workplaces, of which 55 agreed to participate (response rate $=$ $17.4 \%$ ). During the initial recruiting phases, each of the 316 workplaces was contacted by phone. If they agreed to participate, a contact person within each of the workplaces (usually an occupational health and safety officer or human resources personnel) was asked to distribute surveys to desk-based staff, defined broadly as typically working in a sitting position at a workstation or desk for prolonged periods. During the survey period, there were no ongoing initiatives to reduce sitting time at the sampled workplaces. Participants were asked to return the questionnaires to the researchers via a reply paid envelope. A total of 1,622 surveys were distributed at the 55 workplaces, of which 801 were returned (response rate $=49.3 \%$ ). The survey was conducted between February and April 2009. The study protocol was approved by the Deakin University Ethics Committee.

\section{Measures}

\section{Total and domain specific sitting time}

An adapted version of the previously validated domain-specific sitting questionnaire by Marshall et al. ${ }^{29}$ was used to assess time spent sitting in occupational and leisure-time domains respectively. ('During the last 7 days, how much time did you usually spend sitting at work?' and 'During the last 7 days, how much time did you usually spend sitting during your leisure-time?') Participants were asked to provide separate responses for weekdays and weekend days. Transport-related sitting was assessed using questions from the long form of the International Physical Activity Questionnaire (IPAQ-long) - http://www.ipaq.ki.se. ('During the last 7 days, how many days did you travel in a motor vehicle like a train, bus, car or tram?' and 'How much time did you usually spend on one of those days travelling in a train, bus, car or tram?') These questions have been shown to have acceptable reliability and validity. ${ }^{30}$ We altered the Marshall et al. questions to keep their wording consistent with the transport-related sitting and physical activity questions from the IPAQ-long. Therefore, the reliability and validity for our adapted questions has not been assessed.

Weekly time spent in transport-related sedentary behaviour was calculated by multiplying the reported frequency and duration. Weekly duration of occupational and leisure-time sitting was calculated by summing weekday sitting minutes multiplied by five and weekend day sitting minutes multiplied by two. Domain-specific sitting time (mins/day) in each of the three settings was summed to estimate the total weekly sitting time.

\section{Socio-demographic and lifestyle characteristics}

Participants reported their sex, age, education level, main occupation (coded according to the Australian Standard Classification of Occupation [ASCO] coding system, 1997), number of hours worked in the previous week and weight and height. Participants' responses were collapsed to: age $18-29,30-44,45-59$ and $\geq 60$ years; level of education $<12$ years, 12 years or trade/technical qualification and university education; and occupation type white collar occupations (i.e. managers, administrators, professionals, associate professionals) and blue collar occupations (i.e. trades persons, advanced clerical, intermediate clerical and other (ASCO, 1997). Body mass index (BMI) was computed from self-reported height and weight $\left(\mathrm{kg} / \mathrm{m}^{2}\right)$ and collapsed to: normal or underweight $(\mathrm{BMI}<25)$; overweight (BMI 25-30); and obese (BMI $\geq 30) .{ }^{31}$ We used the IPAQ-long to assess the time spent in physical activity within the transport, occupational and leisure-time domains during the past seven days. Data on the time spent in moderate and vigorous-intensity physical activity were used to categorise participants as sufficiently active ( $\geq 150$ mins/week of moderate or $\geq 75$ mins/week of vigorousintensity physical activity or an equivalent combination of both) or insufficiently active according to the Australian physical activity recommendations..$^{15}$ The IPAQ-long physical activity estimates have previously shown adequate reliability and validity. ${ }^{32}$ Detailed description of IPAQ-long physical activity data processing protocols can be found elsewhere (http://www.ipaq.ki.se).

\section{Data analyses}

Data analyses used IBM SPSS Statistics 21 (SPSS Inc. an IBM Company, Chicago, IL, USA). Since the sitting data were not normally distributed they are presented as medians, $95 \%$ confidence intervals $(95 \% \mathrm{Cl})$ for medians based on bootstrapping (1,000 resamples) and interquartile ranges (IQR). A Kruskal-Wallis ANOVA was performed to test the differences in sitting time between sex, age, education, occupational, BMl and physical activity categories. Multiple linear regression analyses were conducted to investigate associations between sex, age, education, occupational category, BMI and physical activity level (set of independent variables) and total, occupational, leisure-time and transport-related sitting (dependent variable). The regression models 
were tested for: 1) multicollinearity using the variance inflation factors (VIF); 2) normality of residuals using the normal probability plot and histogram of residuals; and 3) heteroscedasticity using the standardized residuals vs. predicted plot. The VIFs ranged from 1.01 to 1.28 for independent variables in the regression models, indicating no multicollinearity. Other regression assumptions were also met for all regression models. Only slight non-normality of residuals was found when modelling transport-related sitting. To normalise the distribution of residuals in the model, the time spent in transportrelated sitting was log-transformed, but no interpretative differences were observed in the output (data not shown). A significance level for all analyses was set at 0.05 .

\section{Results}

Table 1 shows the socio-demographic and lifestyle characteristics of the participants. Responses to sitting questions were missing for seven participants ( $0.8 \%$ of total sample). Therefore, the final analyses included 794 employees. The sample comprised a greater proportion of women; just over half were classified as being overweight or obese (BMI $\geq 25$ ) and a similar percentage reported having white collar occupations. More than half were aged 45 years or younger, had more than 12 years education, and more than three-quarters were sufficiently physically active. Almost $90 \%$ of the sample was made up of full-time employees.
The median total sitting time across all domains was 540 minutes/day, or 9 hours/ day (Table 1). Medians for work, leisure-time and transport-related sitting time were 300,171 and 60 minutes/day, respectively, representing $\sim 56 \%, \sim 32 \%$ and $\sim 11 \%$ of total daily sitting time, respectively. Total and domain-specific sitting time did not differ significantly by sex, but total sitting time was higher among those who were classified as insufficiently active, aged between 18 and 29 years of age, working in blue collar occupations and had 12 years of education (557-578 minutes/day). Adults aged $\geq 60$ years had the lowest median sitting time in the work domain (257 minutes/day). The highest median leisure-time sitting was found for

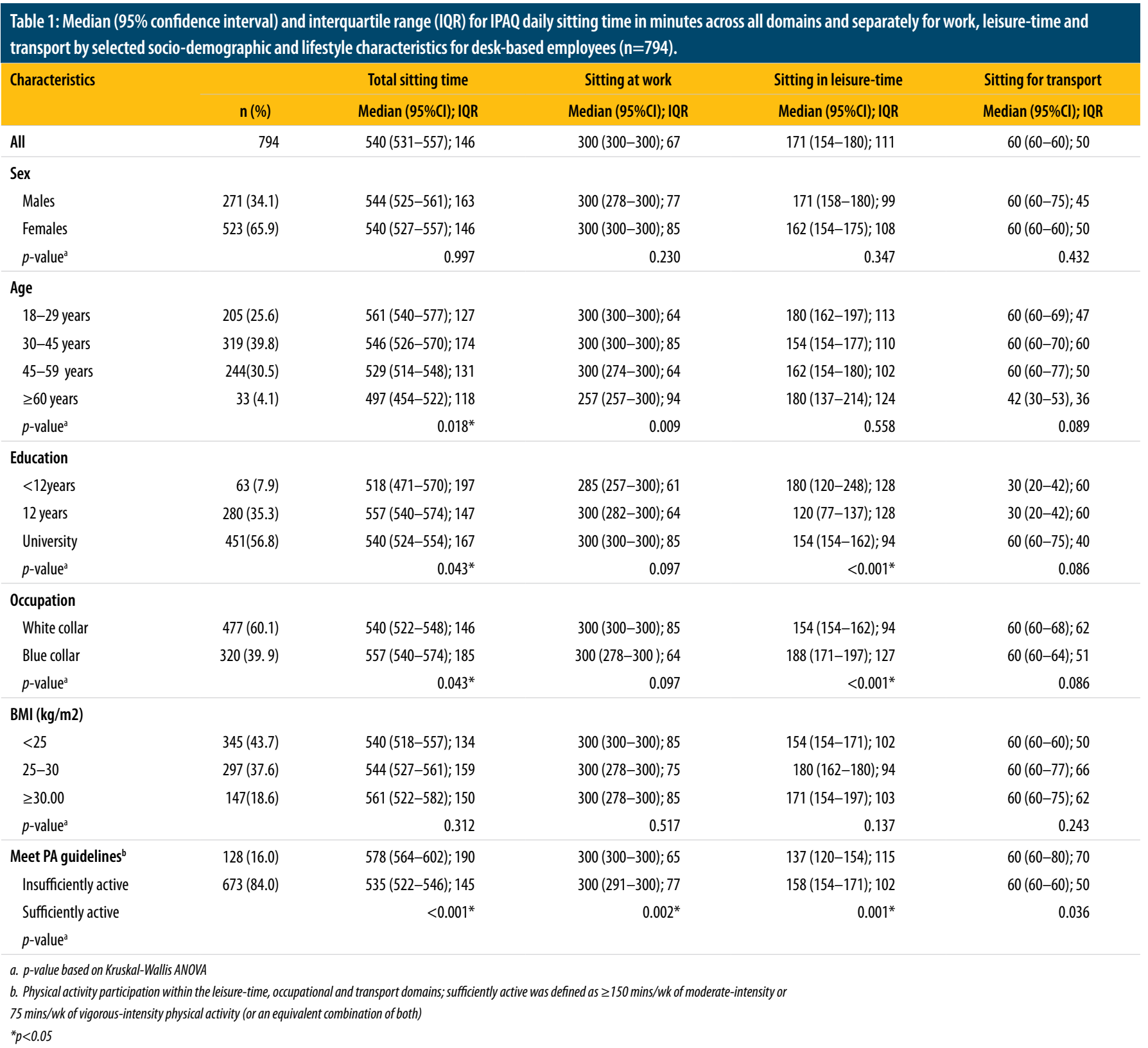


blue collar workers (188 minutes/day) and the lowest for people with 12 years of education (120 minutes/day). There were no significant differences observed across groups for transport-related sitting.

Table 2 shows the results of multiple linear regression analyses. The set of independent variables explained $2.5 \%, 3.1 \%$ and $2.3 \%$ of the variance of total, occupational and leisure-time sitting $(p<0.01$ for all). No significant relationship was found with transport-related sitting (multiple $\mathrm{R}=0.12$, $p=0.12$ ). Sex and education level did not show significant associations with total and domain-specific sitting. Age was inversely related to occupational (unstandardised regression coefficient $[B]=-0.71, p=0.003$ ) and leisure-time sitting $(B=-0.66, p=0.039)$. A tenyear increase in age was associated with an average of 15.8 minutes/day less total sitting time $(p<0.001)$. Being a white collar worker was associated with more sitting at work (7.38 mins/day, $p=0.08$ ) and less leisure-time sitting (20.69 mins/day, $p=0.011$ ). Body mass index was positively related to total $(B=1.53$, $p=0.038)$, leisure-time $(B=1.22, p=0.032)$ and transport-related sitting $(\mathrm{B}=0.57, p=0.046)$, but not to occupational sitting ( $\mathrm{B}=0.20$, $p=0.854$ ). MVPA (minutes/week) was inversely related to total $(B=-0.03, p<0.001)$ and leisuretime sitting $(B=-0.02, p<0.001)$. Hours worked during the previous week was positively associated with higher total sitting time $(B=-$
$1.39, p=0.003)$ and occupational sitting time $(\mathrm{B}=1.38, p<0.001)$.

\section{Discussion}

This study showed that in Australian employees from desk-based workplace settings, an average of nine hours of the day was occupied by sitting, of which a large proportion was accrued at work. Higher total sitting time was associated with younger age groups, higher BMI and lower MVPA. Several socio-demographic and lifestyle variables were significantly associated with occupational and leisure-time sitting, but not with transport-related sitting.

The median total sitting time of nine hours/day observed in the present study is consistent with what has been reported in other samples of employees in Australia. ${ }^{22,26}$ By contrast, sitting time was 1.5 times the amount of sitting time that has been reported in population samples of young and midaged Australian women ${ }^{28}$ and more than two times higher than has been reported in the Australian general population. ${ }^{16}$ This difference might be partially accounted for by the use of different questionnaires. For example, Bauman et al. ${ }^{16}$ used a singleitem total sitting time measure from the International Physical Activity Questionnaireshort form (IPAQ-short) to assess the sitting levels of Australian adults, whereas the present study and other studies ${ }^{22,26}$ have used a domain-specific questionnaire. Moreover, given that the present study recruited employed adults who mostly sat for their working tasks, it is likely that the higher sitting volumes than those previously reported reflect the restriction of our sample to adults working in desk-based settings. The amount of occupational sitting time reported by the participants in the present study was similar to that reported by Miller, ${ }^{22}$ but $~ 50-$ 100 minutes/day higher than in other studies on Australian workers. ${ }^{23,26,27,33}$ However, Chau et al. ${ }^{20}$ found even higher occupational sitting time in a population sample of Australian employees who mostly sit for their working tasks. Our findings support the assumption that employees in desk-based professions spend more time sitting at work than other working populations. In contrast, the volume of leisure-time sitting found in the present study was approximately the same ${ }^{34}$ or lower than in other working populations. ${ }^{26,27}$ Furthermore, the median of one hour per day spent sitting during transportation was consistent with other working populations in Australia. ${ }^{22,34}$ Based on these findings, it seems to be the case that transport-related sitting time does not differ between employees with more or less sedentary jobs.

An important question to consider when interpreting our results is whether the sitting volumes observed in our sample are likely to

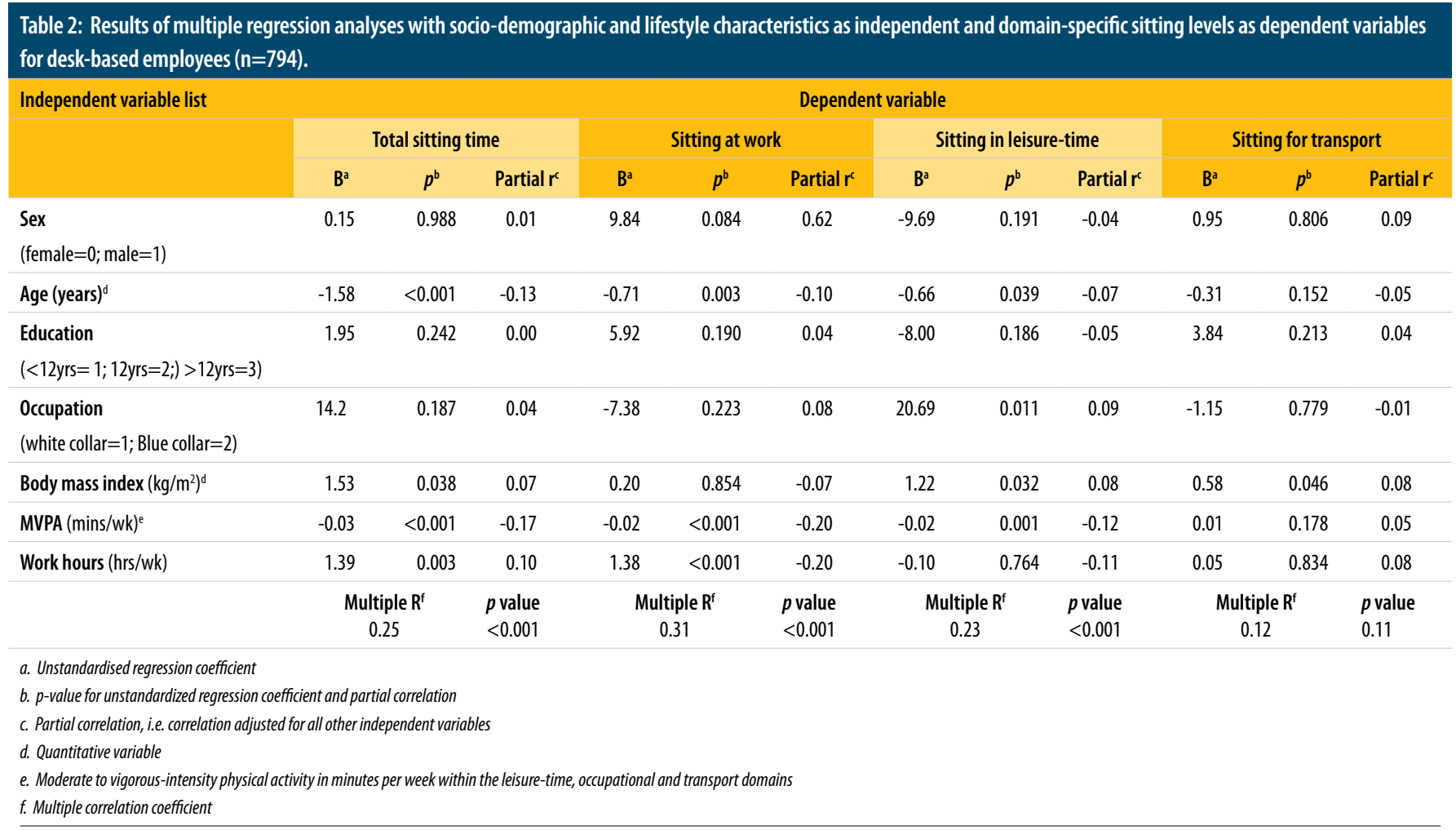


lead to negative health outcomes. At present, there is no consensus among researchers regarding the estimated limit of daily sitting that may induce detrimental health consequences. A recent meta-analysis of prospective studies provided some evidence to suggest that self-reported total daily sitting $\geq 600$ minutes/day ( 10 hours/day) is associated with a $34 \%$ increase in mortality risk after adjustment for leisure-time physical activity. ${ }^{35}$ Further replication of these findings is needed before this sitting volume becomes a recognised threshold. Nevertheless, 30.5\% of our sample reported total daily sitting for $\geq 600$ minutes/day, which indicates that a significant number of desk-based employees may be at an increased risk of all-cause mortality due to high sitting levels. Moreover, research has shown that individuals commonly underestimate their daily sitting time. ${ }^{3}$ Therefore, the sitting times of deskbased employees are likely to be even higher than those found in the present study.

A novel aspect of this study was that it examined how desk-based employees' daily sitting time is distributed across different domains. Our results identified that in desk-based employees, work-related sitting accounts for more than half of daily sitting time. Leisure-time and transport domains accounted for about one-third and just over $10 \%$ of daily sitting, respectively. Therefore, workplace sitting reduction interventions may have significant potential to reduce total sitting in desk-based employees. Recent controlled intervention trials have investigated the feasibility of reducing workplace sitting in office-based workers. These studies have provided some promising evidence of the short-term (e.g. 4-12 weeks) effectiveness for reducing occupational sitting by providing workers with sit-tostand work desks, ${ }^{36-38}$ a combined approach of installing sit-to-stand work desks and providing support at a management/ organisational level, ${ }^{37}$ or specifically designed computer prompting software to reduce workplace sitting. ${ }^{39,40}$ However, at present, the long-term effectiveness in reducing sitting time and the effects on health outcomes of such interventions remains unknown.

The present study helps identify distribution of sitting across different domains, which may inform the development of domainspecific interventions to reduce sitting. When compared to those in white collar occupations, blue collar employees reported higher total daily sitting levels. The data suggested that higher leisure-time sitting levels were the likely cause of this finding. This result is consistent with findings from previous research on the socio-demographic of leisure-time sitting volumes, ${ }^{18}$ and suggests that sitting reduction strategies may target leisure-time sitting among blue collar employees. Such sitting reduction interventions may target the most common sedentary activities in leisure-time, including TV viewing and other screen-based entertainment (computer or video game use). Although studies have suggested that strategies to reduce sitting during the leisure-time may include standing during commercial breaks ${ }^{19}$ or using active gaming platforms, ${ }^{42}$ the long-term effectiveness of such strategies has not been examined.

A linear regression analysis showed that age and MVPA are inversely related to total sitting time after adjustment for other sociodemographic and lifestyle characteristics. These results are in accordance with previous research, ${ }^{18}$ and highlight the importance of targeting younger and less physically active desk-based employees in future sitting interventions among desk-based workers. Furthermore, the regression analyses revealed that BMI was significantly related to leisuretime and transport-related sitting, but not to occupational sitting. These findings are in concordance with previous research that has shown a mixed relationship between sitting at work and BMI status, ${ }^{43}$ and more consistent associations between high levels of leisure-time ${ }^{18}$ and transport-related sitting and higher BMI. ${ }^{44,45}$ Finally, our results clearly show that correlates of sitting are domain-specific. For example, white collar occupations showed positive associations with occupational sitting, negative associations with leisure-time sitting and no association with transport-related sitting. This underscores the importance of assessing of domain-specific sitting time in future studies, as conclusions based solely on total sitting time may be misleading.

A limitation of the study was that the sample was predominantly women, and had low proportions of overweight/obese individuals and high proportions of blue-collar workers, sufficiently active and well-educated adults. However, given the present study aimed to recruit a sample of adults in desk-based work settings who predominately sit for working tasks, we did not intend our findings to be generalisable to the whole population. Another limitation of this study was the use of self-reported sitting time data. It has been recommended that, whenever possible, sedentary behaviour studies should use both self-report and objective measures. ${ }^{3}$ However, a constraint when using objective instruments is that without potentially onerous written logs and diaries, objective instruments do not provide information on the domain or context of the behaviour. ${ }^{46}$ Also, there are some logistical issues (such as, adherence to wearing of the units) and costs associated with the use of accelerometry or inclinometers in population studies. For such reasons, self-report surveys remain the most common sitting assessment method. ${ }^{47}$ Further study limitations included the fact that the sampling process did not allow for recruitment of a 'true' random sample of workplaces and employees. Also, we did not assess the disability status of the participants. Moreover, once the surveys were delivered to work settings, it was not possible to assess what were the motivating factors that may have influenced study participation. In addition, the use of selfreported physical activity levels and height and weight may lead to misinterpretations of the results. However, previous research has shown acceptable agreement between BMI estimates based on self-reported and measured height and weight. ${ }^{48}$

The major strengths of this study include: 1) the assessment and separate analysis of domain-specific sitting volumes and its correlates; and 2) a large sample of adults who commonly sit for working tasks and are, therefore, potentially susceptible to negative outcomes associated with excessive sitting.

\section{Conclusion}

This study showed that desk-based employees spend excessive time sitting, with workplace sitting being a major contributor. Given the high contribution of occupational sitting to overall sitting time, interventions could focus on reducing sitting time in the work setting. Public health strategies to reduce daily sitting levels in desk-based workers should particularly focus on younger, overweight/obese and insufficiently active individuals, as it seems that they are at the highest risk of this health-risk behaviour. 


\section{References}

1. Owen N, Bauman A, BrownW.Too much sitting: a novel and important predictor of chronic disease risk? $\mathrm{Br} J$ Sports Med. 2009;43(2):81-3.

2. Sedentary Behaviour Research Network. Standardized use of the terms "sedentary"and "sedentary behaviours". Appl Physiol Nutr Metab. 2012;37:540-2.

3. Healy GN, Clark BK, Winkler EA, Gardiner PA, Brown WJ, Matthews CE. Measurement of adults' sedentary time in population-based studies. Am J Prev Med. 2011;41(2):216-27.

4. Bauman A, Chau J, Ding D, Bennie J. Too much sitting and cardio-metabolic risk: An update of epidemiological evidence. Curr Cardiovasc Risk Rep. 2013;7(4):293-8.

5. Thorp AA, Owen N, Neuhaus M, Dunstan DW. Sedentary behaviors and subsequent health outcomes in adults a systematic review of longitudinal studies, 1996-2011. Am JPrev Med. 2011;41(2):207-15

6. Wilmot EG, Edwardson CL, Achana FA, Davies MJ, Gorely T, Gray $L$, et al. Sedentary time in adults and the association with diabetes, cardiovascular disease and death: Systematic review and meta-analysis. Diabetologia. 2012;55(11):2895-905

7. Katzmarzyk PT, Church TS, Craig CL, Bouchard C. Sitting time and mortality from all causes, cardiovascular disease, and cancer.Med SciSportsExerc. 2009;41(5):9981005.

8. Matthews CE, George SM, Moore SC, Bowles HR, Blair A, Park Y, et al. Amount of time spent in sedentary behaviors and cause-specific mortality in US adults. Am J Clin Nutr. 2012;95(2):437-45.

9. Patel AV, Bernstein L, Deka A, Feigelson HS, Campbell PT, Gapstur SM, et al. Leisure time spent sitting in relation to total mortality in a prospective cohort of US adults. Am J Epidemiol. 2010;172(4):419-29.

10. van der Ploeg HP, Chey T, Korda RJ, Banks E, Bauman A. Sitting time and all-cause mortality risk in 222497 Australian adults. Arch Intern Med.2012;172(6):494-500.

11. Ding D, Rogers K, Macniven R, Kamalesh V, Kritharides $\mathrm{L}$, Chalmers J, et al. Revisiting lifestyle risk index assessment in a large Australian sample: Should sedentary behavior and sleep be included as additional risk factors? Prev Med. 2014;60:102-6.

12. Herber-Gast GC, Jackson CA, Mishra GD, BrownWJ.Selfreported sitting time is not associated with incidence of cardiovascular disease in a population-based cohort of mid-aged women. Int J Behav Nutr Phys Act. 2013;10(1):55.

13. Garber $C E$, Blissmer $B$, Deschenes MR, Franklin BA, Lamonte MJ, Lee IM, et al. American College of Sports Medicine position stand. Quantity and quality of exercise for developing and maintaining cardiorespiratory, musculoskeletal, and neuromotor fitness in apparently healthy adults: Guidance for prescribing exercise. Med Sci Sports Exerc. 2011;43(7):1334-59.

14. Tremblay MS, Leblanc AG, Janssen I, Kho ME, Hicks A, Murumets K, et al. Canadian sedentary behaviour guidelines for children and youth. Appl Physiol Nutr Metab. 2011;36(1):59-64; 5-71.

15. Brown W, Bauman A, Bull F, Burton N. Development of Evidence-based Physical Activity Recommendations for Adults (18-64 Years). Canberra (AUST): Commonwealth Department of Health; 2012.
16. Bauman A, Ainsworth BE, Sallis JF, Hagstromer M, Craig $\mathrm{CL}$, Bull FC, et al. The descriptive epidemiology of sitting A 20-country comparison using the International Physical Activity Questionnaire (IPAQ). Am J Prev Med. 2011;41(2):228-35.

17. Bennie JA, Chau JY, van der Ploeg HP, Stamatakis E, Do A, Bauman A. The prevalence and correlates of sitting in European adults - a comparison of 32 Eurobarometerparticipating countries. Int J Behav Nutr Phys Act. 2013;10(1):107.

18. Rhodes RE, Mark RS, Temmel CP. Adult sedentary behavior: A systematic review. Am J Prev Med. 2012;42(3):e3-28.

19. Owen N. Sedentary behavior: understanding and influencing adults' prolonged sitting time. Prev Med. 2012;55(6):535-9.

20. Chau JY, van der Ploeg HP, Dunn S, Kurko J, Bauman AE. A tool for measuring workers' sitting time by domain: The Workforce Sitting Questionnaire. Br J Sports Med. 2011;45(15):1216-22.

21. Jans MP, Proper KI, HildebrandtVH. Sedentary behavior in Dutch workers: Differences between occupations and business sectors. Am J Prev Med. 2007;33(6):450-4

22. Miller R, Brown W. Steps and sitting in a working population. Int J Behav Med. 2004;11(4):219-24.

23. Mummery WK, Schofield GM, Steele R, Eakin EG, Brown WJ. Occupational sitting time and overweight and obesity in Australian workers. Am J Prev Med. 2005;29(2):91-7.

24. Thorp AA, Healy GN, Winkler E, Clark BK, Gardiner PA Owen $\mathrm{N}$, et al. Prolonged sedentary time and physical activity in workplace and non-work contexts: A crosssectional study of office, customer service and cal centre employees. Int J Behav Nutr Phys Act. 2012;9:128

25. Toomingas $A$, Forsman $M$, Mathiassen $S E$, Heiden $M$ Nilsson T. Variation between seated and standing/ walking postures among male and female call centre operators. BMC Public Health. 2012;12:154.

26. Vandelanotte C, Duncan MJ, Short C, RockloffM, Ronan K, Happell B, et al. Associations between occupational indicators and total, work-based and leisure-time sitting: A cross-sectional study. BMC Public Health 2013;13(1):1110.

27. Chau JY, van der Ploeg HP, Merom D, Chey T, Bauman AE. Cross-sectional associations between occupational and leisure-time sitting, physical activity and obesity in working adults. Prev Med. 2012;54(3-4):195-200.

28. van Uffelen JGZ, Heesch KC, Brown W. Correlates of sitting time in working age Australian women: Who should be targeted with interventions to decrease sitting time? J Phys Act Health. 2012;9(2):270-87.

29. Marshall AL, MillerYD, Burton NW, BrownWJ. Measuring total and domain-specific sitting: A study of reliability and validity. Med Sci Sports Exerc. 2010;42(6):1094-102.

30. Rosenberg DE, Bull FC, Marshall AL, Sallis JF, Bauman $A E$. Assessment of sedentary behavior with the International Physical Activity Questionnaire. J Phys Act Health. 2008;5 Suppl 1:S30-44.

31. World Health Organisation. Obesity: Preventing and Managing the Global Epidemic. Report of a WHO Consultation. World Health Organ Tech Rep Ser. 2000;894:i-xii, 1-253.

32. Craig CL, Marshall AL, Sjostrom M, Bauman AE, Booth $\mathrm{ML}$, Ainsworth BE, et al. International physical activity questionnaire: 12-country reliability and validity. Med SciSports Exerc. 2003;35(8):1381-95.
33. Kilpatrick M, Sanderson K, Blizzard L, Teale B, Venn A. Cross-sectional associations between sitting at work and psychological distress: Reducing sitting time may benefit mental health. Ment Health Phys Act. 2013;6(2):103-9.

34. Brown WJ, Miller YD, Miller R. Sitting time and work patterns as indicators of overweight and obesity in Australian adults. Int J Obes Relat Metab Disord. 2003:27(11):1340-6.

35. Chau JY, Grunseit AC, Chey T, Stamatakis E, Brown WJ, Matthews $C E$, et al. Daily sitting time and all-cause mortality:A meta-analysis. PLoSOne.2013;8(11):e80000.

36. Alkhajah TA, Reeves MM, Eakin EG, Winkler EA Owen N, Healy GN. Sit-stand workstations: A pilot intervention to reduce office sitting time. Am J Prev Med. 2012;43(3):298-303.

37. Cooley $D$, Pedersen S. A pilot study of increasing nonpurposeful movement breaks at work as a means of reducing prolonged sitting. J Environ Public Health. 2013:2013:128376.

38. Evans RE, Fawole HO, SheriffSA, Dall PM, Grant PM, Ryan CG. Point-of-choice prompts to reduce sitting time at work: A randomized trial. Am J Prev Med. 2012;43(3): 293-7.

39. Healy GN, Eakin EG, LaMontagne AD, Owen N, Winkler EAH, Wiesner $\mathrm{G}$, et al. Reducing sitting time in office workers: Short-term efficacy of a multicomponent intervention. Prev Med. 2013;57(1):43-8.

40. Pronk NP, Katz AS, Lowry M, Payfer JR. Reducing occupational sitting time and improving worker health: The Take-a-Stand Project, 2011. Prev Chronic Dis. 2012;9(10):110323.

41. Gardiner PA, Eakin EG, Healy GN, Owen N. Feasibility of reducing older adults' sedentary time. Am J Prev Med. 2011;41(2):174-7.

42. Miyachi M, Yamamoto K, Ohkawara K, Tanaka S. METs in adults while playing active video games: A metabolic chamber study. Med Sci Sports Exerc. 2010;42(6):114953.

43. van Uffelen JGZ, Wong J, Chau JY, van der Ploeg HP, Riphagen I, Gilson ND, et al. Occupational sitting and health risks a systematic review. Am J Prev Med. 2010;39(4):379-88.

44. Frank LD, Andresen MA, Schmid TL. Obesity relationships with community design, physical activity, and time spent in cars. Am J PrevMed. 2004:27(2):87-96.

45. Sugiyama T, Ding D, Owen N. Commuting by car: Weight gain among physically active adults. Am J Prev Med. 2013;44(2):169-73.

46. Westerterp KR. Assessment of physical activity: A critical appraisal. Eur J Appl Physiol. 2009;105(6):823-8.

47. Clark BK, Winkler E, Healy GN, Gardiner PG, Dunstan DW, Owen N, et al. Adults' past-day recall of sedentary time: Reliability, validity, and responsiveness. Med Sci Sports Exerc. 2013;45(6):1198-207.

48. Ng SP, Korda R, Clements M, Latz I, Bauman A, Bambrick $\mathrm{H}$, et al. Validity of self-reported height and weight and derived body mass index in middle-aged and elderly individuals in Australia. Aust NZ J Public Health 2011;35(6):557-63. 